$13^{\text {th }}$ International Conference on

\title{
Mechanical Properties of 6013-T6 Aluminium Alloy Friction Stir Welded Plate
}

\author{
Haşim KAFALI", Nuran AY**
}

\begin{abstract}
Aluminium alloys are widely used on aircraft structures especially on the fuselage and wing fairings. During the joining of these structures, the traditional technique riveting is used. But riveting increases the structural weight of the aircraft and rivet holes form stress concentration for the fatigue cracks. An alternative joining technique is welding. In traditional welding techniques metal is heated till the melting point for this reason the mechanical behavior of the material deteriorates. And also the weldability of high strength materials is low. In recent years Friction Stir Welding (FSW) has been used as an alternative joining technique. In this study T6 heat treatment is applied to Aluminium 6013 sheet and this sheet joined by using FSW technique. Tensile specimens were machined from the welded plate in the dimension of $\mathrm{A}_{0}=12.5 \mathrm{~mm}, 1_{0}=200 \mathrm{~mm}$ and tensile tests were performed. Vickers microhardness values were taken at $1 \mathrm{~mm}$ increments from base metal to base metal across the weld, on the weld cross-sections. The intermetallic particles and the grain structure of the welded sheet were examined via optical and scanning electron microscopy.
\end{abstract}

Keywords: Friction Stir Welding, Tensile Tests, Microstructural Evaluation, Al 6013-T6

\section{Introduction}

Friction stir welding (FSW) is a simple, clean and innovative joining technology for light metals invented by The Welding Institute (TWI), in 1991. Due to the high strength of FSW joints, it allows considerable weight savings in lightweight construction compared to conventional joining technologies. A use of welded instead of riveted joints is also interesting because of the lower production costs. Therefore, the FSW process has recently been identified as key technology for fuselage and wing manufacturing by leading aircraft manufactures [1-6].

In FSW a rotating pin emerging from a cylindrical shoulder is plunged between two pieces of shoot and mound forward along the joint line. The material is heated by friction between the rotating shoulder and the work piece surface and simultaneously stirred by the profiled pin leaving a solid phase bond between the two pieces to be joined. Special preparations of the weld seam and filler wire are not required. In contrast to conventional welding technologies,

\footnotetext{
* Research Asst., Anadolu University School of Civil Aviation, Turkey , hkafali@anadolu.edu.tr

** Prof. Dr., Anadolu University Material Science and Engineering Department, Turkey
} 
the FSW process takes place in the solid phase below the melting point of the metals to be joined. Thus, all the problems related to the solidification of a fused material are avoided. Materials classified as difficult to fusion weld like the high strength aluminum alloys used in the aerospace, industry could be joined with minor loss in strength $[1-4,6]$.

The material that has been used in this study is $6 \mathrm{xxx}$ series aluminum alloy. This material is widely employed in aerospace applications because of some favorable characteristics: high mechanical strength, high fatigue resistance, low sensibility to high temperature and good corrosion resistance. And also these alloys have good formability, weldability, machinability, corrosion resistance, and medium strength. 6xxx series alloys can be strengthened by heat treating and cold-working (controlled deformation at room temperature). The $\mathrm{T}$ temper specification indicates a solution heat-treatment, and the 6 indicates a specific sequence of basic treatments. The 6013-T6 is hence a solution heat-treated and artificially aged alloy that is generally not cold-worked after solution heat-treatment. The mechanical properties are improved by precipitation heat treatment [7-17].

In this paper the acceptability of the weld quality of the Al 6013-T6 sheets compared with previous studies, have been investigated. The aim of the present work was to characterize the microstructure of the nugget and of the heat affected zone (HAZ) as compared to the base material (BM) of Al 6013-T6 alloy. Tensile test were performed and microscopic investigation was combined with microhardness measurement to understand the microstructural changes associated with the welding process.

\section{Experimental}

The material studied was $3.6 \mathrm{~mm}$ AA6013 sheet, which chemical composition is given in Table 1, aged to the $\mathrm{T} 6$ condition (solution heat treated at $550{ }^{\circ} \mathrm{C}$ and water quenched followed by artificial ageing at $175{ }^{\circ} \mathrm{C}$ for 6 hours) and subsequently Friction Stir Welded by Germany Aerospace Center (DLR). Welding was carried out at $1000 \mathrm{~mm} / \mathrm{min}, 1200 \mathrm{rpm}$. Pin and shoulder diameters were $6 \mathrm{~mm}$ and $18 \mathrm{~mm}$, respectively. Welding was carried out perpendicular to the primary rolling direction. Two identical welds were supplied and these welding conditions are typical conditions for this alloy.

Table 1. Chemical Composition of the 6013 Base Material [3,4]

\begin{tabular}{|c|c|c|c|c|c|c|c|c|c|}
\hline Element & $\mathbf{M g}$ & $\mathbf{S i}$ & $\mathbf{C u}$ & $\mathbf{M n}$ & $\mathbf{F e}$ & $\mathbf{C r}$ & $\mathbf{Z n}$ & $\mathbf{T i}$ & $\mathbf{A l}$ \\
\hline $\mathbf{W t}$ (pet) & 0.90 & 0.72 & 0.95 & 0.36 & 0.27 & 0.03 & 0.07 & 0.02 & bal \\
\hline
\end{tabular}

After having the base materials welded; tensile tests and hardness profile of both welded joints and base materials have been performed in order to make a mechanical characterization. Tensile tests have been performed by computer controlled Instron 8500 Servo Hydraulic Universal Test Machine which has $200 \mathrm{KN}$ static and $100 \mathrm{KN}$ dynamic load capacity. Standard tensile tests were carried out and tensile specimens were been prepared in accordance with ASTM E 466 standards. The surfaces of the specimens were machined off and the specimen dimensions have been given in Fig. 1. The local strain was measured in the weld and in the base material.

Vickers microhardness testing performed on the weld cross-sections provided microhardness profiles that revealed the compensation of the normal degradation of 6013-T6 Al in the HAZ, by using Buehler Digital Microhardness Tester MMT-3. 


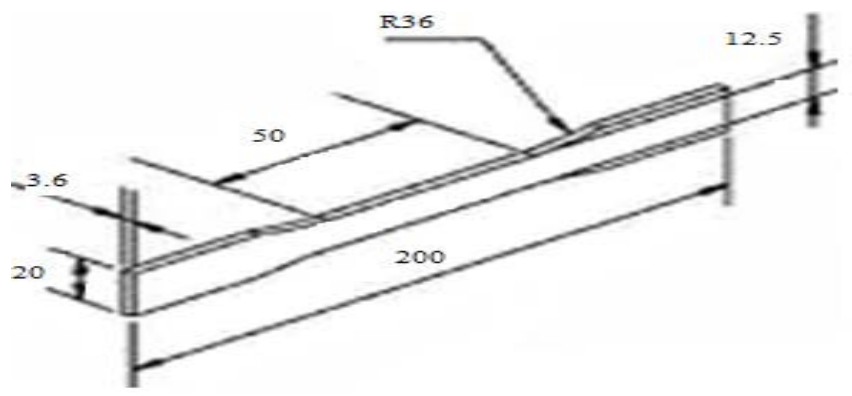

Figure 1. Tensile specimen

The Vickers hardness values were taken at about $1 \mathrm{~mm}$ increments from base metal to base metal across the weld, at a depth of 1,5 $\mathrm{mm}$ from the surface of the welded sheet. Vickers micro-hardness was carried out with $100 \mathrm{gf}$ load and $15 \mathrm{~s}$ dwell time. It was also noticed that all the welds showed very high and erratic microhardness values in the weld zone, in comparison to the base material. Microhardness measurements and tensile tests were carried out 3 months after welding.

In addition to mechanical characterization, extensive microstructural investigations have been performed by optical and scanning electron microscopy. Standard metallographic techniques were applied to prepare samples for optical microscopy (OM) and Zeiss Supra 50VP FEG attached with Oxford Instrument EDX-7430T scanning electron microscopy (SEM). The samples were mechanically polished. During polishing firstly sandpaper and then diamond was used. After polishing, etching was carried out in $0.5 \%$ aqueous solution of hydrofluoric acid.

\section{Results and Discussion}

The microstructural evaluation of the $\mathrm{Al} \mathrm{6013i,} \mathrm{that} \mathrm{has} \mathrm{been} \mathrm{heat} \mathrm{treated} \mathrm{in} \mathrm{T} 6$ condition, has been investigated. SEM images of the base material are shown in Fig. 2. As it can be seen in the Fig. 2a, the base material is determined by a recrystalized microstructure with equiaxed grains. EDX images have been taken from different parts of Fig. 2b. The chemical compositions were approximately same to each other in this EDX results and one of the points taken was spectrum 2 that was shown on Fig. 2c. The EDX results invariably identify $\mathrm{Mg}_{2} \mathrm{Si}$ as the predominant precipitate in all the joint variations [1-4, 18]. As reported from the previous studies, the major precipitate in 6000 series $\mathrm{Al}-\mathrm{Mg}-\mathrm{Si}$ alloy system is $\mathrm{Mg}_{2} \mathrm{Si}$. The formation and distribution of these precipitates depend on solution treatment and aging treatment $[2,18]$.

The $0.2 \%$ offset yield strength; ultimate tensile strength and percentage of joint efficiency were recorded. The ratio between the tensile strength of a welded joint and the tensile strength of unwelded base metal is known as the joint efficiency. The tensile tests in the T6 condition showed that fracture always occurred in the HAZ. Failure took place approximately as a 45 deg shear surface and was accompanied with some necking. The average tensile properties of our material are given in Table 2 which has been composed of from different specimens. Compared to the base material, specimens tested transverse to the weld exhibit reduced strength and ductility. The unwelded base metal showed a yield strength and tensile strength of $330 \mathrm{MPa}$ and $375 \mathrm{MPa}$, respectively. However, the yield strength and tensile strength of the as-welded (AW) joints were $207 \mathrm{MPa}$ and $281 \mathrm{MPa}$, respectively. This indicates a 25$35 \%$ reduction in strength for the FSW joints. 

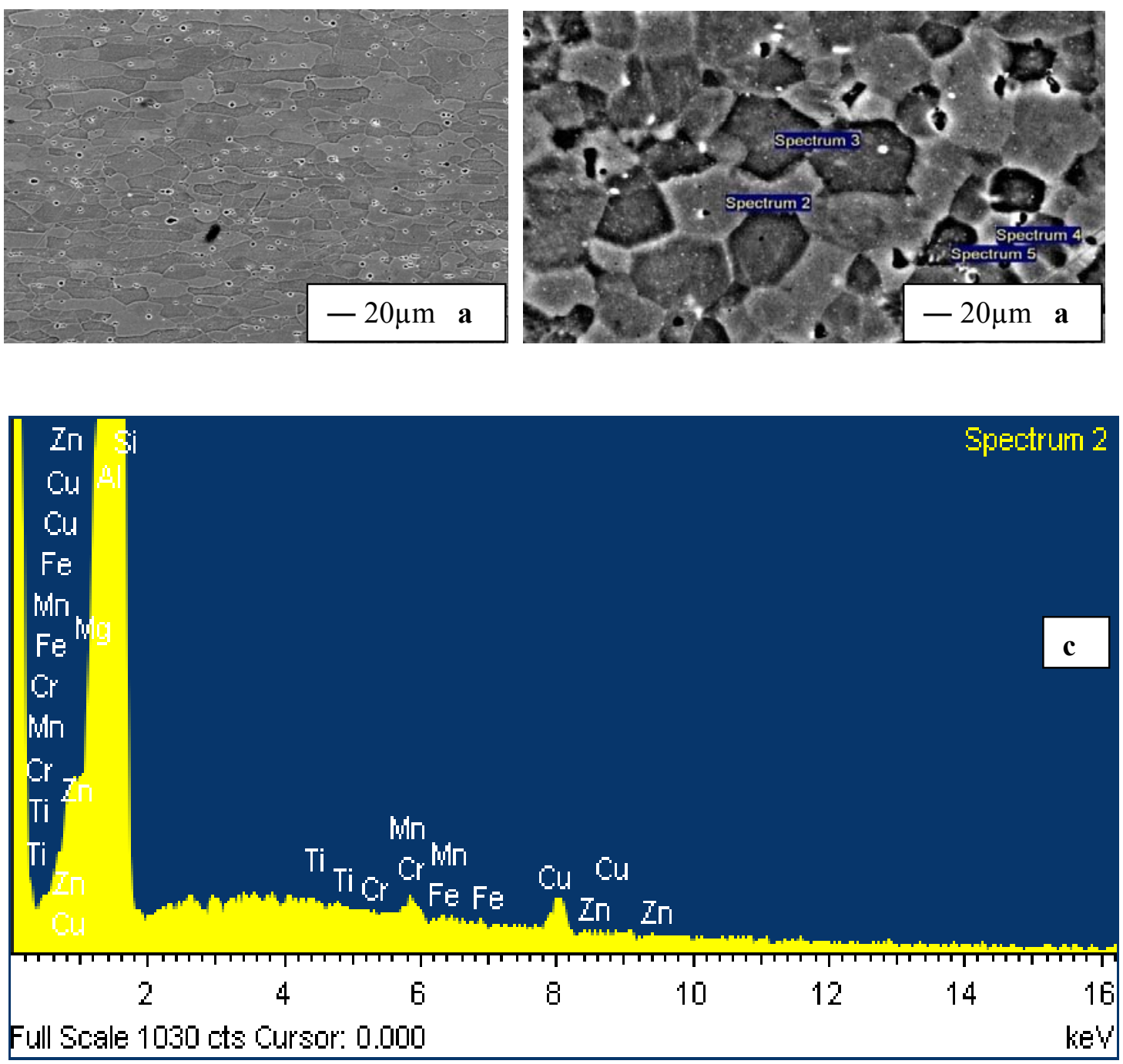

Figure 2. (a) SEM images of the base material, (b) SEM images of the base material, (c) EDX results for AA6013-T6

Table 2. Tensile test results of base and friction stir welded AA 6013 T6 sheets.

\begin{tabular}{|c|c|c|c|c|c|}
\hline Material & $\begin{array}{c}\text { Young's } \\
\text { Modulus } \\
{[\mathrm{MPa}]}\end{array}$ & $\begin{array}{c}\text { Stress at } \\
\text { 0.2\% Yield } \\
\text { Strength } \\
{[\mathrm{MPa}]}\end{array}$ & $\begin{array}{c}\text { Stress at } \\
\text { Max. Load } \\
\text { (ultimate tensile } \\
\text { strength) } \\
{[\mathrm{MPa}]}\end{array}$ & $\begin{array}{c}\text { Joint } \\
\text { Efficiency }\end{array}$ & $\begin{array}{c}\text { UTS }_{\text {FSW }} \\
\text { [UTS }_{\text {Base }} \\
{[\%]}\end{array}$ \\
\hline 6013-T6 Base & 31804 & 330 & 375 & & \\
\hline 6013-T6 FSW & 32453 & 207 & 281 & 64 & 75 \\
\hline
\end{tabular}


A Vickers microhardness testing machine Buehler Digital Microhardness Tester MMT-3 was used to measure the hardness across the weld cross section of the FSW joints; the measured values are obtained and the diagram drawn in Fig. 3. The base metal in the condition T6 showed average hardness value of $135 \mathrm{HV}$, but in the as-welded joint the hardness was average $100 \mathrm{Hv}$ in the FSW zone. The weld zone is considerably softer than the BM. This softening is observed within about 13 to $15 \mathrm{~mm}$ of both sides of the weld centerline $(x=0)$. Similar results with respect to the shape of the microhardness curves were reported by previous studies [1-7]. The HAZ is soft and it behaves in a ductile manner during mechanical loading [1-4].

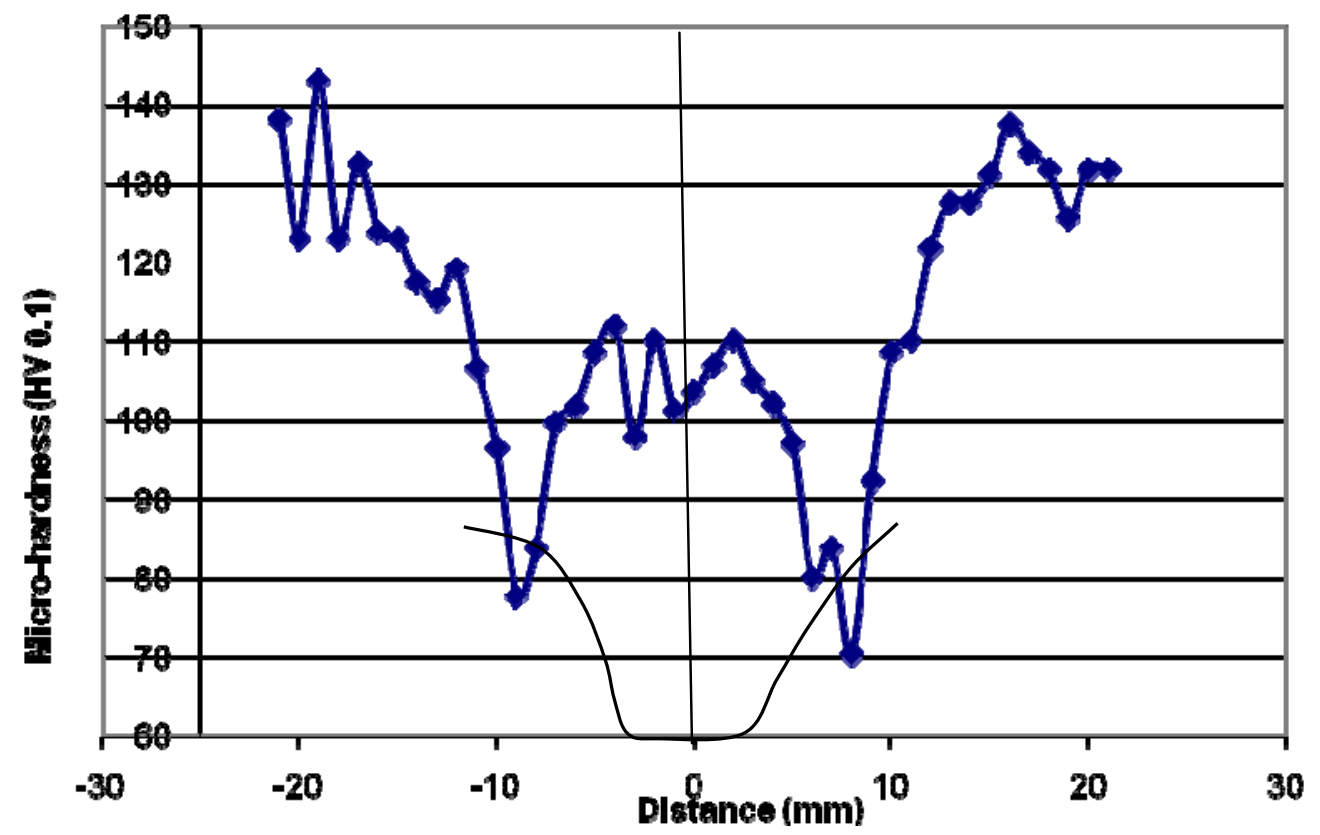

Figure 3. Hardness profiles of base material and welded material

Welding affects the microstructure of the material so the effected zones have been investigated. The macrostructure and microstructure of welded materials are shown in Fig.4 and Fig. 5. A macroscopic image of the welded sheet material is shown in Fig. 4. The weld zone is clearly visible in the low-magnification overview of Fig.4a because of its different contrasts developed after etching. The welding direction is in the line of sight. The weld zone is $\mathrm{V}$-shaped and widens near the top surface because of the close contact between the shoulder of the tool and the upper surface. A weld nugget was noticeable and very distinct. The shape of the weld zone likely depends on the welding parameters and the material. Differences between the advancing and retreating sides of the weld are also apparent, with a more clearly defined edge to the weld on the advancing side as well as an extended section of the nugget near the material top surface, also on the advancing side, and the 'onion ring' structure of the nugget. Studies have shown that the reduction in strength in 6013-T6 friction stir welds is caused by the dissolution, coarsening and transformation of the strengthening $\beta\left(\mathrm{Mg}_{2} \mathrm{Si}\right)$ precipitates. The increased capacity for plastic deformation as a result would be expected to cause a concomitant increase in fracture toughness [1-5, 18]. 
The coarse intermetallic particles formed during solidification are broken up and aligned in the rolling direction during alloy processing, which can result in property anisotropy, especially in terms of crack propagation. The significant material redistribution associated with the friction stir welding process results in redistribution of these particles, which will have implications in terms of crack propagation within the weld $[1-5,18]$.

The butt joining of AA6013 T-6 to itself was successfully welded by friction stir welding.. The microstructure of FSW joints can be separated to four zones; first base material; second heat affected zone (HAZ); third thermo-mechanical affected zone (TMAZ); and fourth weld nugget.

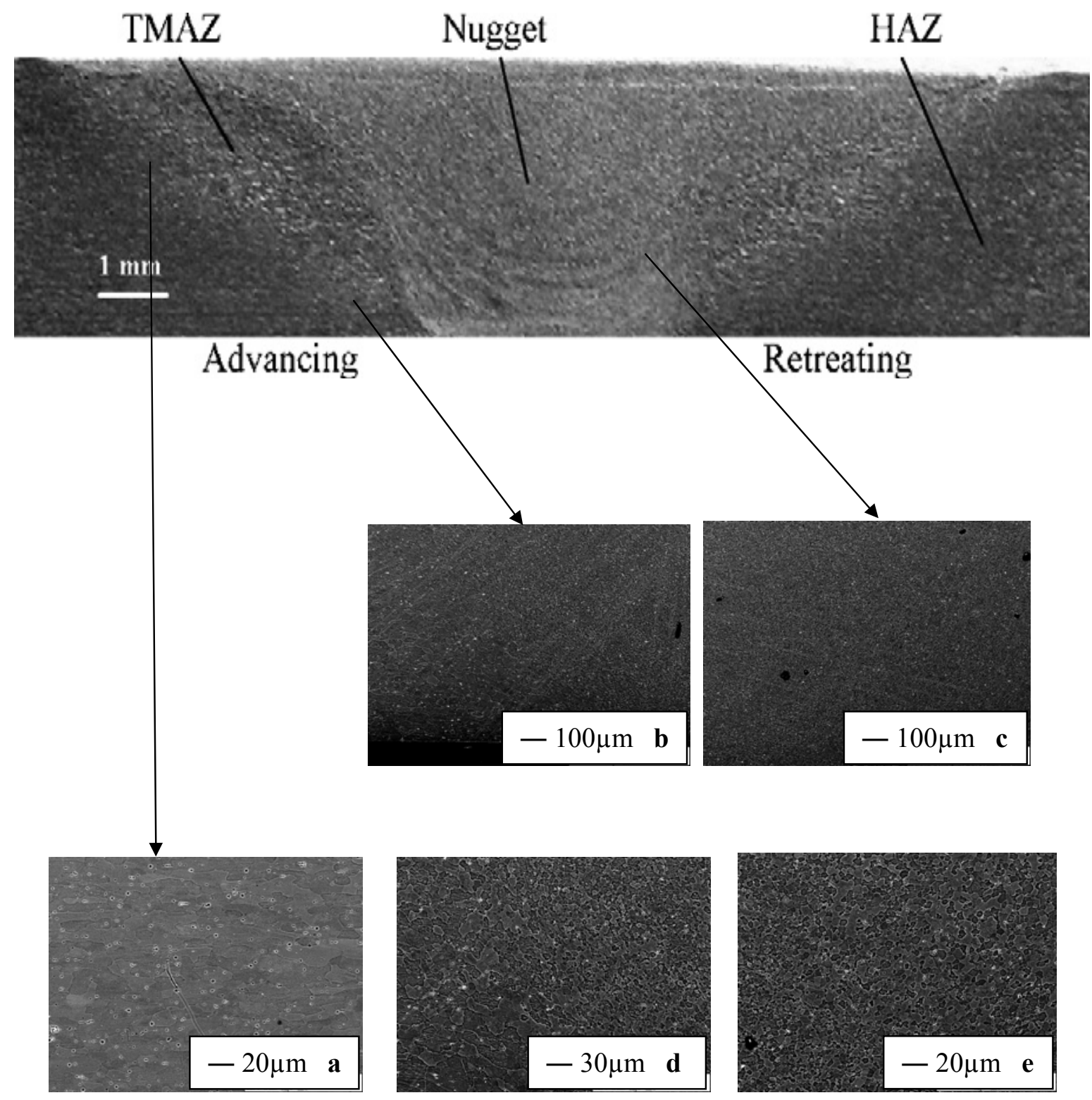

Figure 4. AA6013-T6 FSW macro-image 


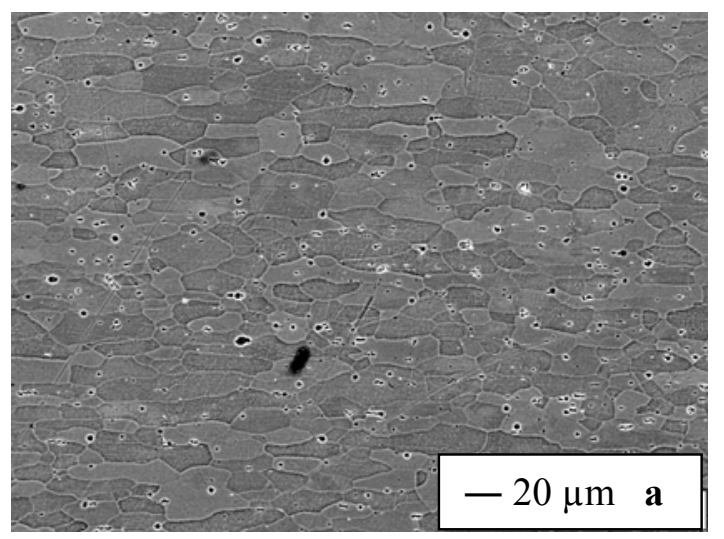

(a) base material

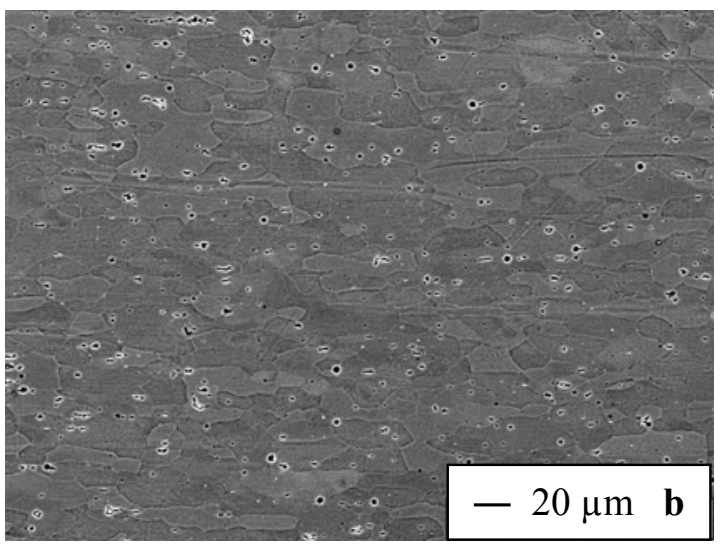

(b) heat affected

zone (HAZ);

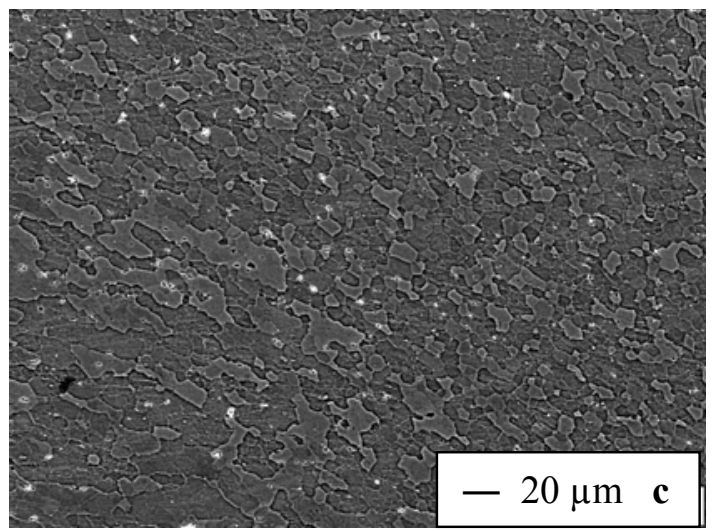

(c) thermo-mechanical

affected zone

(TMAZ)

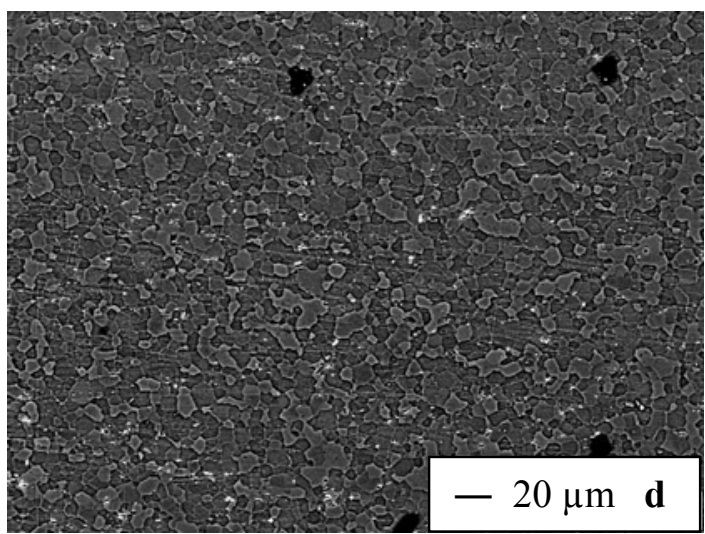

(d) weld nugget.

Figure 5. Optical microstructures (SEM images) of FSW joint of 6013 T-6 


\section{Conclusions}

The butt joining of AA6013 T-6 to itself was successfully carried out using a friction stir welding technique. The tensile, microstructure, microhardness and EDX analysis of friction stir welded AA6013 T-6 have been studied in the present work. The following conclusions have been optained:

- The microstructure of the welding zone in the friction stir welded AA6013 T-6 was divided into four zones are base material, heat affected zone (HAZ), thermo-mechanical affected zone (TMAZ) and weld nugget.

- EDX measurements clearly show that both the parent material and the weld region consist of relatively homogenous distributions of the fine and coarse $\mathrm{Mg}_{2} \mathrm{Si}$ particles. Uniformly distributed, finer strengthening $\mathrm{Mg}_{2} \mathrm{Si}$ precipitates, smaller grain size, the lack of a precipitate free zone, and higher dislocation density are the reasons for the superior tensile properties of the FSW joints.

- The base material exhibits average hardness value of $130 \mathrm{HV}$ while the weld nugget has an average hardness of $100 \mathrm{HV}$. The average hardness values in the TMAZ are slightly lower than in the weld nugget.

- Joints exhibited a joint efficiency of $64-75 \%$.

- Friction stir welding results in a dynamically recrystallized grain structure in the weld nugget with smaller grain size than in the BM. Such dynamically recrystallized grains are equiaxed compared to the elongated grains observed in the rolled BM.

- Fine equiaxed grains in the FSW region implies that dynamic recrystallization has taken place during friction stir welding due to plastic deformation.

\section{Acknowledgments}

The authors express their appreciation to M.SC. Ulises Alfaro Mercado, German Aerospace Center (DLR) Koeln Germany, for providing the FSW material. The authors acknowledge the help rendered by Erhan Ayas for experimental assistance for available SEM facility to analyze the samples. The authors also wish to express their sincere thanks to Assit. Prof. Serdar Dalkılıç for all his endless help in any step of the study. 
Paper: ASAT-13-MS-14

\section{References}

[1] Derry, C.G. and J.D. Robson, Characterisation and modelling of toughness in 6013-T6 aerospace aluminium alloy friction stir welds. Materials Science and Engineering: A, 2008. 490(1-2): p. 328-334.

[2] Elangovan, K. and V. Balasubramanian, Influences of post-weld heat treatment on tensile properties of friction stir-welded AA6061 aluminum alloy joints. Materials Characterization, 2008. 59(9): p. 1168-1177.

[3] HEINZ, B. and B. SKROTZKI, Characterization of a Friction Stir Welded Aluminum Alloy 6013. Metallurgical and Materials Transactions B, 2002. 33B: p. 489-498.

[4] Rodrigues, D.M., et al., Influence of friction stir welding parameters on the microstructural and mechanical properties of AA 6016-T4 thin welds. Materials \& Design, 2008. In Press, Corrected Proof.

[5] Troeger, L.P. and E.A. Starke, Microstructural and mechanical characterization of a superplastic 6xxx aluminum alloy. Materials Science and Engineering A, 2000. 277(12): p. 102-113.

[6] Mishra, R.S. and Z.Y. Ma, Friction stir welding and processing. Materials Science and Engineering: R: Reports, 2005. 50(1-2): p. 1-78.

[7] Braun, R., Investigations on the long-term stability of 6013-T6 sheet. Materials Characterization, 2006. 56(2): p. 85-95.

[8] Chen, Y.C. and K. Nakata, Microstructural characterization and mechanical properties in friction stir welding of aluminum and titanium dissimilar alloys. Materials \& Design, 2009. 30(3): p. 469-474.

[9] Fersini, D. and A. Pirondi, Analysis and modelling of fatigue failure of friction stir welded aluminum alloy single-lap joints. Engineering Fracture Mechanics, 2008. 75(34): p. 790-803.

[10] Heinz, A., et al., Recent development in aluminium alloys for aerospace applications. Materials Science and Engineering A, 2000. 280(1): p. 102-107.

[11] Heinz, B. and B. Skrotzki, Characterization of a friction-stir-welded aluminum alloy 6013. Metallurgical and Materials Transactions B-Process Metallurgy and Materials Processing Science, 2002. 33(3): p. 489-498.

[12] Leal, R.M. and A. Loureiro, Effect of overlapping friction stir welding passes in the quality of welds of aluminium alloys. Materials \& Design, 2008. 29(5): p. 982-991.

[13] Liu, H.J., et al., Tensile properties and fracture locations of friction-stir-welded joints of 2017-T351 aluminum alloy. Journal of Materials Processing Technology, 2003. 142(3): p. 692-696.

[14] Scialpi, A., et al., Mechanical analysis of ultra-thin friction stir welding joined sheets with dissimilar and similar materials. Materials \& Design, 2008. 29(5): p. 928-936.

[15] Tesch, A., et al., Short cracks initiated in Al 6013-T6 with the focused ion beam (FIB)technology. International Journal of Fatigue, 2007. 29(9-11): p. 1803-1811.

[16] Williams, J.C. and E.A. Starke, Progress in structural materials for aerospace systems. Acta Materialia, 2003. 51(19): p. 5775-5799.

[17] Williams, S.W., Welding of airframes using friction stir. Air \& Space Europe, 2001. 3(3-4): p. 64-66.

[18] Buha, L., Crosky, Microstructural Development and Mechanical Properties of interruped Aged Al-Mg-Si-Cu Alloy Metallurgical and Materials Transactions A, 2006. 37A: p. 3119-3130. 